\title{
Democracia: velhas e novas controvérsias $^{1}$
}

\author{
Antônio Cabral Neto \\ Universidade Federal do Rio Grande do Norte
}

\begin{abstract}
Resumo:
A discussão realizada neste artigo busca sistematizar elementos essenciais em torno do tema democracia. Sistematiza fragmentos da democracia dos antigos; analisa a origem e evolução da democracia dos modernos, explicitando a sua relação com o liberalismo e discute a relação democracia e bem-estar social em países de capitalismo avançado e no Brasil. A conclusão sinaliza para a necessidade de ampliação da democracia, articulando as suas dimensões política, chave: econômica e cultural. Isso implicaria a incorporação Democracia, organizada dos atores sociais aos processos políticos e Política, administrativos e o acesso da população aos bens materiais, Igualdade, culturais e educacionais.

Exclusão.
\end{abstract}

Key-words: Democracy, Politics, Participation, Freedom, Exclusion

\begin{abstract}
:
Democracy: old and new controversies. In this article the author searches for clarification of essential elements around the theme democracy. He analyses fragments of old democracy, the origin and evolution of modern democracy, making clear its relationship with liberalism. He also discusses the relationship between democracy and social well being in countries of advanced capitalism and Brazil. The conclusion identifies the need for the expansion of democracy, articulating its political, economic and cultural dimensions. This would imply in an organised linking of the social actors to political and administrative processes, as well as the access of the population to goods, both cultural and educational.
\end{abstract}




\begin{abstract}
democracia é um tema bastante antigo e explorado por vários $\triangle$ autores. Entretanto, configura-se, na atualidade, como uma 1 Cárea de estudo bastante significativa, por apresentar-se contemporaneamente como o regime defendido por quase todas as correntes de pensamento, independente de suas concepções políticas e ideológicas. É certo, porém, que no embate político a defesa da democracia assume perspectivas diversas. Este artigo coloca-se na direção de sistematizar elementos que possam contribuir para o debate dessa temática. $\mathrm{O}$ eixo central da análise situa-se na perspectiva de explicitar, em cada experiência particular, a configuração que assumiu a relação inclusão-exclusão dos atores sociais no jogo democrático.
\end{abstract}

\title{
Sobre a democracia dos antigos
}

A democracia, na forma como foi evidenciada desde a antigüidade até os dias atuais, traz em si um conjunto de contradições que redundou numa maior ou menor incorporação da população ao jogo democrático.

Em sua forma histórica, a democracia dos antigos, expressa na experiência ateniense, era uma democracia direta que se realizava num espaço restrito - a cidade/Estado grega. Ela, a democracia, se processava por intermédio de um sistema de assembléias, às quais era atribuído o poder de tomar todas as decisões políticas. O comparecimento à assembléia era teoricamente permitido a todo cidadão, não havia burocracia e o governo era exercido pelo povo.

A condição de cidadania em Atenas, todavia, era adquirida apenas por pessoas do sexo masculino, com mais de dezoito anos de idade, filhas de pai e mãe atenienses. É possível indicar que a democracia ateniense, no plano das idéias, buscava criar as condições estruturais para assegurar, a todo aquele que tivesse adquirido o status de cidadão, a participação no controle dos negócios públicos. Apenas os cidadãos estavam credenciados para usufruírem plenamente dos direitos civis e políticos, podendo, por conseguinte, participar diretamente do governo e de suas instituições políticas (assembléias deliberativas e as magistraturas).

A democracia ateniense foi, dessa forma, marcada por fortes elementos de exclusão, na medida em que não se estendia a toda população. Dela foram excluídos os metecos - estrangeiros 
domiciliados em Atenas, na sua grande maioria gregos de outras regiões - que, mesmo estando obrigados a pagar impostos e a prestar o serviço militar, tinham vedada a participação em cargos públicos por não pertencerem à demos. Foram igualmente excluídos os escravos, que constituíam a grande parte da população, as mulheres e os jovens com idade inferior a dezoito anos.

Ao mesmo tempo em que o corpo político na democracia ateniense era constituído por uma elite minoritária, havia também problemas no interior mesmo da própria categoria dos cidadãos no que diz respeito às possibilidades reais de participação.

Teoricamente, a assembléia era integrada por todos os cidadãos, porém, na prática, o número dos que a ela compareciam era, segundo os registros históricos, relativamente pequeno. A freqüência à eclésia (assembléia popular) era uma prática mais constante entre os trabalhadores e negociantes da cidade os quais, pela sua localização geográfica, encontravam mais facilidades para exercerem os direitos políticos, do que os habitantes do interior e do litoral, que a ela compareciam com pouca intensidade. A freqüência dos segmentos mais ricos da população urbana à assembléia era, também, pouco significativa, visto que esses setores, tradicionalmente, tinham um comportamento reticente frente ao regime democrático (Burns, 1957; Finley, 1988).

Os estudos que tratam dessa problemática destacam a existência de indícios os quais sugerem que apenas um número reduzido de cidadãos exerciam o direito de falar na Assembléia. Era depositada em alguns líderes uma certa credibilidade no sentido de formular as linhas da conduta política a ser seguida. Entretanto, a decisão sobre a adoção ou não dessa política cabia sempre à assembléia popular e não ao líder. Nesses termos, o reconhecimento por parte do corpo político da necessidade de ter uma liderança não implicava, em hipótese alguma, a renúncia do seu poder decisório.

O corpo político da democracia ateniense era formado por membros considerados absolutamente iguais, porque todos eram livres. A liberdade era o critério que determinava a igualdade. A liberdade era, segundo Aristóteles, "o princípio da prática democrática”. Porém, 
a igualdade do corpo político, na democracia ateniense, era apenas política e não econômica, na medida em que era constituído por grupos de origem social bastante diversificada. Dela faziam parte a aristocracia, que trazia consigo todos os hábitos da nobreza; a classe média rural, constituída por agricultores que ansiavam por liberdade; e a população urbana integrada pelos negociantes, industriais e trabalhadores de todas as categorias, que, ao lado de segmentos da população rural, formavam um forte sustentáculo das idéias democráticas.

O nível de instrução não era um fator determinante para a condição de cidadão. No corpo político da democracia ateniense conviviam, lado a lado, os camponeses, comerciantes e artesãos, que possuíam um baixo nível de instrução, com as classes mais elevadas, possuidoras de uma instrução mais aprimorada. Porém, teoricamente todos deveriam gozar dos mesmos direitos políticos. Já entre os metecos, que não eram considerados cidadãos, existiam intelectuais do mais alto gabarito (Miron, Zeuxis, Hipódamos de Mileto, Hipócrates, Aristóteles, por exemplo).

Naquela época, a educação formal não tinha, pois, o mesmo significado e importância que assume hoje nas discussões sobre democracia e cidadania. No entanto, o clima democrático vivido em Atenas favoreceu enormemente o desenvolvimento intelectual. Ela foi a cidade na qual residiram os primeiros historiadores e acolheu os sofistas gregos, responsáveis pela elaboração de conhecimentos originais para aquela época (Sócrates, Platão, Aristóteles, Heródoto, dentre outros).

A democracia ateniense, ao se circunscrever nos limites de uma sociedade escravocrata, trazia no seu interior as contradições e os limites próprios dessa forma de organização social.

A democracia dos antigos era restrita, tanto no sentido de que excluía grande parte de população da vida política, quanto no sentido de que aqueles que teoricamente deveriam ter acesso a ela, na prática, não usufruíam igualmente nem dos diretos políticos, nem dos bens materiais produzidos naquele momento.

A democracia que assegurava, no plano formal, a igualdade política a todos os cidadãos, no plano real convivia com uma desigualdade material, o que, certamente expressava o caráter limitativo da participação política. 
Há de se considerar, todavia, que tal democracia criou um conjunto de instituições políticas que permitiu viabilizar, dentro dos limites da época, uma experiência de expressivo significado histórico. Além da participação direta na vida política, a democracia ateniense era dotada de mecanismos que permitiam responsabilizar todos os ocupantes de postos perante o corpo político. Ela exercia, por exemplo, uma ampla fiscalização sobre a sua magistratura, que mesmo sendo escolhida por sorteio, deveria ser submetida a exame prévio (dokimasia) e a uma devassa completa na sua vida pública e particular, e, ao terminar o mandato, a uma rigorosa prestação de contas perante uma comissão de fiscais públicos.

\section{Democracia representativa e democracia direta}

Após a derrota da experiência democrática dos antigos, resultante da guerra desencadeada entre os anos 431 e 404 A. C., a democracia praticamente desapareceu do cenário político. Por toda a Idade Média e, notadamente, a partir do século XV, com o florescimento do ideário absolutista - que serviu de sustentáculo aos governos despóticos - os ideais democráticos saíram de cena por um longo período histórico.

É com o constitucionalismo moderno, dois mil anos depois, que a questão da democracia ressurge no panorama político, pela mão dos federalistas, que em seus argumentos contrapõem a democracia direta dos antigos à democracia representativa, como sendo esta a única forma de governo popular viável nos Estados modernos. Essas idéias estão fartamente expostas na obra $O$ federalista, escrita por Madison, Hamilton e Joy. Para esses autores, a democracia representativa era a forma de governo em que o povo não participava diretamente da tomada de decisão sobre os temas de seu interesse, mas escolhia os seus representantes que deveriam tomar por ele tais decisões.

O grande desenvolvimento do pensamento democrático se processou, no entanto, no seio das revoluções burguesas que eclodiram nos séculos XVII e XVIII na Europa. Essas revoluções engendraram e, ao mesmo tempo, se fundamentaram no ideário liberal que, ao lado da democracia moderna, se constitui em produto do capitalismo.

A democracia dos modernos se edifica tomando como referência o ideário liberal que, de início, era avesso aos direitos democráticos 
mais abrangentes. O pensamento liberal que serve de fundamento para a democracia dos modernos subordina a condição de cidadão à propriedade privada. O status de cidadão, segundo as formulações do liberalismo clássico, conquista-se na sua relação com a propriedade. O estatuto de cidadão está subordinado à propriedade - é cidadão quem é proprietário. Essa visão tem como desdobramento uma perspectiva restrita de democracia, ou seja, a democracia que está na base do pensamento liberal é, na verdade, a democracia dos proprietários.

Entretanto, o liberalismo e a democracia, apesar das contraposições históricas que se manifestaram entre eles durante uma longa fase, uniram-se para a formação da democracia liberal.

\section{Liberalismo e democracia representativa}

As bases do pensamento liberal se encontram nas formulações de Locke, que, ao teorizar sobre a sociedade inglesa do século XVII, em pleno desenvolvimento da manufatura, defendia a construção de um Estado da autoridade legislativa baseado na igualdade natural. Para o autor, o Estado deveria garantir o exercício e a segurança de propriedade, uma vez que o homem, com o objetivo de garantir a sua propriedade, sente a necessidade de colocar limites à sua própria liberdade.

A igualdade natural proposta por Locke é uma igualdade que se concretiza no trabalho. $\mathrm{O}$ Estado seria a corporificação da forma da autoridade legislativa, que asseguraria a continuidade da reprodução sistemática da igualdade natural entre os homens, tendo como primado o trabalho. O excedente, elemento da desigualdade, manifestaria a conseqüência aleatória de sua própria natureza, ou seja, resultaria da ganância.

Locke representava as idéias da burguesia que se consolidava em decorrência das transformações em curso na sociedade inglesa, cujo marco chegou a revelar-se na chamada revolução gloriosa de 1688. Daí toda a sua teorização trazer implícita a necessidade de se erigir uma ordem civil capaz de garantir o direito de propriedade. Para ele: “... qualquer sociedade política não pode existir nem subsistir sem ter em si o poder de preservar a propriedade - isto é, a vida, a liberdade e os bens - contra os danos e ataques de outros homens ..." (Locke, 1983, p. 67).

Nesses termos, a igualdade defendida pelo ideário liberal no plano do direito só seria alcançada na relação de propriedade. 
Entretanto, como observa Marshall (1967, p. 63), “...o direito de propriedade não é o direito de possuir propriedade, mas um direito de adquiri-la, caso possível, e de protegê-la, se puder tê-la".

Seguindo essa mesma trilha, Paulo Netto (1990) sugere que os direitos de participação que podem saturar a ordem civil fundam-se expressamente na propriedade privada. Lembra, ainda, que "A cidadania conceptualizada pela teoria liberal é impensável sem a propriedade (privada). A democracia (política) identifica-se com a liberdade do proprietário - indivíduo livre e cidadão são sinônimos pela indispensável mediação de propriedade" (p. 19).

Historicamente, o caráter formal da igualdade não se expressou apenas no campo econômico. Ela se manifestou, também, no plano político. O sufrágio universal na Europa do século XIX, por exemplo, era um privilégio dos detentores de propriedade ou daqueles que pagavam uma certa quantia de impostos, ficando, dessa forma, excluída a maior parte da população do direito de votar. O voto universal masculino foi um direito conquistado apenas no final do século XIX e início do século XX, sendo o voto feminino uma vitória bem mais recente.

O direito de associação foi, também, de início dificultado em países de orientação liberal. Em 1791, quando estava em vigor o regime resultante da Revolução Francesa, foi promulgada a Lei Le Chapelier que proibia a formação de associações operárias. Somente em 1864 foi admitido o direito de greve, e o reconhecimento legal dos sindicatos foi conquistado apenas em 1884. O primeiro partido político de massa - o Partido da Social - Democracia Alemã - foi criado em 1870. Todos esses avanços foram alcançados, historicamente, com o desenrolar de grandes lutas sociais, das quais participou ativamente a classe operária.

Assim, a concepção liberal é, no seu nascedouro, politicamente discriminatória. Não é o liberalismo, segundo Cerroni (1993), que põe o problema da universal igualdade do gênero humano: o sufrágio universal, igualdade das mulheres, paridade dos trabalhadores não são metas do pensamento liberal. No entanto, diz Cerroni que compete:

... ao liberalismo a proclamação do princípio geral da igualdade de 'dignidades', que abre as portas a todas as ulteriores reivindicações universalistas dos direitos. É por isso que o liberalismo, sem pro- 
mover esta reivindicação, acaba por torná-la possível e posteriormente a acolhe" (1993, p. 63).

A teoria liberal não se desenvolve nos seus primórdios como teoria política democrática. Ela recolhe antes "as demandas democráticas num arcabouço teórico-prático que as repõem sobre um patamar restrito." (Paulo Netto, 1990, p. 14)

O grande mérito histórico do liberalismo é, no entanto, o reconhecimento da igualdade individual, ainda que essa igualdade seja a igualdade formal. $\mathrm{O}$ fato do ideário liberal reconhecer formalmente que todos os homens são iguais perante a lei, representou um significativo avanço para a história da humanidade. Porém, não significou que, na prática, esse direito fosse viabilizado.

Assim, a igualdade que está na base do pensamento liberal é a igualdade jurídica, a igualdade de oportunidade, a qual prevê a equidade dos pontos de partida e não dos pontos de chegada. O direito do cidadão é o direito à igualdade de oportunidade. Seu objetivo é eliminar o privilégio hereditário. É o direito de todos de mostrar e desenvolver diferenças ou desigualdades; o direito igual de ser reconhecido como desigual.

É mister pôr em evidência que, apesar das controvérsias entre liberalismo e democracia, ambos se articulam, em um dado momento histórico, para dar corpo e forma à democracia liberal. O nexo entre liberalismo e democracia repousa no fato de que partem de um ponto comum: o indivíduo.

Como observa Cerroni (1993), a democracia liberal é o resultado da adequação do liberalismo às reivindicações sociais, políticas e jurídicas dos movimentos democráticos. O liberalismo fornece à democracia política não só o fundamento da dignidade igual dos homens, mas também um conjunto de "regras do jogo" vinculadas aos procedimentos necessários para garantir a livre competição dos indivíduos.

A democracia liberal resultou, dessa forma, de uma complexa articulação entre liberalismo e democracia. O encontro de ambos, apesar de não ter se efetuado de forma tranqüila, evidenciou que a democracia não é incompatível com o liberalismo, e que em vários aspectos ela pode ser considerada como seu prosseguimento. 
Segundo Bobbio (1993), a democracia pode ser considerada como um prolongamento natural do Estado liberal, não pelo lado do seu ideário igualitário, mas pela sua fórmula política, que é a soberania popular. Esta tornar-se-ia possível, na medida em que um maior número de cidadãos tivesse o direito de participar direta e indiretamente da tomada das decisões coletivas, significando a extensão dos direitos políticos até o limite último do sufrágio universal masculino e feminino. Bobbio assevera, ainda, que:

Idéias liberais e método democrático vieram gradualmente se combinando num modo tal que, se é verdade que os direitos de liberdade foram desde o início a condição necessária para a direta aplicação das regras do jogo democrático, é igualmente verdadeiro que, em seguida, o desenvolvimento da democracia se tornou o principal instrumento para a defesa dos direitos de liberdade (p. 44).

A democracia moderna no seu nascedouro assume a forma de democracia representativa. A sua marca primeira é a representação política, na qual o representante deve estar voltado para atender aos interesses da nação e não aos interesses particulares dos representados, isto é, o representante não pode ficar sujeito a um mandato vinculado. Aqui, o controle sobre a representação fica praticamente descartado.

A participação direta é radicalmente rejeitada pelos teóricos da democracia moderna. Montesquieu (1979), um dos seus principais teóricos, defendeu no seu livro $O$ Espírito das Leis que: "O povo era excelente para escolher, mas péssimo para governar." Precisava o povo, portanto, de representantes, que iriam decidir e querer em nome do povo.

Tomando Bobbio (1979) como referência, pode-se afirmar que o sistema representativo puro nunca existiu. O Estado representativo sempre teve que prestar contas ao Estado administrativo que é "um Estado que obedece uma lógica de poder descendente e não ascendente, secreta e não pública, hierarquizada e não autônoma, tendente à imobilidade e não à dinâmica, conservadora e não inovadora." (p. 52).

$\mathrm{O}$ autor revela, ainda, que nunca teve dúvidas quanto aos limites reais e insuperáveis do sistema representativo numa sociedade capitalista selvagem como a italiana. Para ele: 
A soberania do cidadão está limitada pelo fato das grandes decisões quanto ao desenvolvimento econômico ou não chegarem aos órgãos representativos ou, se chegarem, serem tomadas [...] em sedes onde a grande maioria dos cidadãos soberanos não tem a menor voz ativa (Bobbio, 1979 p. 52).

A partir dessas formulações, conclui que o defeito de tal sistema não é o de ser representativo, mas de não sê-lo o bastante. Assim, a ampliação da representação passaria, necessariamente, pela criação de condições favoráveis no sentido de que o cidadão passasse a interferir concretamente nas decisões sociais e econômicas por meio dos órgãos de decisão política. A questão, pois, não é a de negar o sistema de representação, mas acionar mecanismos capazes de aperfeiçoá-lo no interior mesmo da sociedade capitalista.

\section{Democracia direta: uma alternativa à democracia representativa?}

Rousseau (1983), teorizando no contexto da sociedade francesa do século XVIII- momento em que a sociedade burguesa, após as revoluções que a edificaram, enfrenta um conjunto de contradições que põe em cheque o próprio ideário que lhe serviu de suporte -, recoloca a questão da participação direta como uma necessidade histórica.

Nesse contexto, segundo Rousseau, há uma sociedade desigual cuja igualdade vai se concretizar no Estado, local onde os elementos desiguais acordam entre si para a criação de um Estado da natureza capaz de suprimir os elementos limitativos da desigualdade reinante entre os homens. Para ele, o homem é bom em si mesmo; o trabalho é o elemento que o prejudica e o corrompe. Daí a necessidade da formulação de um Estado democrático que resgate este princípio de bondade que o homem tem em si próprio.

Para Rousseau, é indispensável a adoção do contratualismo como uma forma de legitimar todas as forças da sociedade, uma vez que a civilização é o elemento perturbador das relações entre os homens e tende a violentar a humanidade. Na sua perspectiva, os homens nascem livres e iguais, mas em todos os lugares estão escravizados pelos grilhões da modernidade civilizatória.

Para superar essas condições, deve-se estabelecer um contrato para fundar a sociedade baseada na igualdade e na liberdade, visto que: 
Renunciar à liberdade é renunciar à qualidade de homem, aos direitos da humanidade, e até aos próprios deveres. Não há recompensa possível para quem tudo renuncia. Tal renúncia não se compadece com a natureza do homem, e destituir-se voluntariamente de toda e qualquer liberdade equivale a excluir a moralidade de suas ações (Rousseau, 1983, p. 27).

Os indivíduos, ao se submeterem às regras contratuais, estariam apenas substituindo a liberdade animal, da qual eram dotados no estado natural, pela real liberdade de seres racionais submetidos à lei. A sujeição dos indivíduos ao Estado resultaria na verdadeira liberdade.

É preciso ter presente que, para Rousseau, o Estado não se restringe ao governo. O Estado é por ele considerado como uma comunidade politicamente organizada, que tem a função soberana de exprimir a vontade geral. A autoridade do Estado não pode ser representada, mas precisa expressar-se diretamente através da promulgação, pelo povo, das leis fundamentais.

Nestes termos, o governo se constitui apenas no agente executivo do Estado tendo, pois, como função, não a formulação da vontade geral, mas simplesmente a tarefa de executá-la. Ademais, a comunidade poderia estabelecer ou destituir o governo no momento em que considerasse oportuno.

Nas formulações de Rousseau, liberdade e igualdade são inseparáveis, de modo que uma não subsiste sem a outra:

... quanto à igualdade, não se deve entender por essa palavra que sejam absolutamente os mesmos graus do poder e de riqueza, mas, quanto ao poder, que seja distanciado de qualquer violência e nunca exerça senão em virtude do posto e das leis e, quanto à riqueza, que nenhum cidadão seja suficientemente opulento para poder comprar o outro e não haja nenhum tão pobre que, se veja constrangido a vender-se... (1983, p. 66).

Admite o autor que a igualdade plena não é possível de se concretizar. Entretanto, essa formulação de Rousseau põe para a discussão um elemento importante, na medida em que expressa o entendimento segundo o qual extremas desigualdades funcionam como elementos 
limitativos da liberdade. Veja-se o que diz o próprio Rousseau: "Tal igualdade, dizem, é uma quimera do espírito especulativo, que não pode existir na prática. Mas, se o abuso é inevitável, segue-se que não precisemos pelo menos regulamentá-lo"? (1983, p. 67).

É evidente que os pressupostos da teoria rousseauniana não contemplam a igualdade absoluta, principalmente no que se refere ao nível de riqueza, mas incluem a defesa de que as desigualdades existentes no campo econômico não deveriam conduzir à desigualdade política.

A igualdade defendida por Rousseau funda-se no princípio da identidade entre os homens, porém, concretamente, não suprime a desigualdade existente entre eles, uma vez que a desigualdade é parte mesma da forma de organização da sociedade dessa época. No dizer de Gruppi, "os homens não nascem nem livres nem iguais, só se tornam assim através de um processo político" (1980, p.18).

A igualdade que Rousseau está buscando no homem é uma igualdade intrínseca ao homem mesmo, isto é, a bondade, a virtude, a moral. É, portanto, a igualdade como expressão da individualidade, ou seja, o homem como essência de si mesmo, da sua bondade.

Seguindo por essa trilha, Rousseau, um dos pais da democracia moderna, em $O$ Contrato Social, formula as primeiras críticas à democracia representativa. No embate com os defensores do Estado parlamentar, o autor afirma que a soberania não pode ser representada. Os deputados do povo, na sua perspectiva, não são seus representantes e não passando de seus comissários, nada podem concluir definitivamente. Rousseau radicaliza o debate sustentando que:

É nula toda lei que o povo diretamente não ratificar; em absoluto, não é lei. O povo inglês pensa ser livre e muito se engana, pois só o é durante a eleição dos membros do parlamento; uma vez estes eleitos, ele é escravo, não é nada. Durante os breves momentos de sua liberdade o uso, que dela faz, mostra que merece perdê-la. (1983, p. 108).

A crítica de Rousseau à democracia representativa pressupõe que o simples ato de votar em eleições não traduz a expressão da vontade 
popular. O autor aponta os limites da democracia representativa e propõe como eixo do que viria a ser o fundamento das exigências democráticas contemporâneas: a participação popular.

Na sua perspectiva, era necessário construir uma democracia direta, na qual o povo fosse capaz de expressar realmente a sua vontade, em contraposição à democracia representativa que a restringia.

A participação direta e individual no processo de tomada de decisão se constituía no eixo básico da teoria política de Rousseau. Nela, a participação tem um caráter educativo. O sistema ideal de Rousseau foi concebido, segundo Patemam (1992), para desenvolver uma ação responsável, individual, social e política como resultado do processo participativo.

A evolução da sociedade moderna trouxe uma série de transformações reais que tornaram problemática a teoria de Rousseau sobre democracia direta. No entanto, deve-se realçar que nela são identificados elementos essenciais do pensamento democrático, principalmente no que se refere a esse caráter educativo da participação.

A defesa da participação direta, como única forma de expressão da soberania defendida por Rousseau, não se aplica em sociedades complexas como as do final do século XX. O próprio Rousseau, já em sua época, tinha a compreensão de que: "Jamais existiu, jamais existirá uma democracia verdadeira"(1983, p. 84).

Essa forma de governo exigiria certas condições difíceis de serem construídas: um Estado muito pequeno, uma grande simplicidade de costumes, bastante igualdade entre as classes e as fortunas, e pouco ou nada de luxo. Sugere, ainda, o autor que: "Se existisse um povo de deuses, governar-se-ia democraticamente. Governo tão perfeito não convém aos homens" (Rousseau, 1983, p. 86).

É preciso reconhecer que a adoção de mecanismos de participação direta da população precisam ser reconstruídos de acordo com as circunstâncias presentes, com vistas à consolidação da democracia possível.

Nesses termos, a democracia direta não deve ser colocada como uma alternativa à democracia representativa, mas como algo complementar. Essa articulação entre democracia representativa e democracia 
direta é uma necessidade histórica, porém será insuficiente se não estiver sintonizada com níveis razoáveis de democracia econômica e cultural.

\section{Democracia politica e bem-estar social}

As transformações ocorridas nos séculos XIX e XX, tanto no campo político quanto no econômico, trazem, no seu interior, elementos que põem a necessidade de aprimorar mecanismos com vistas a ampliar a democracia. A questão colocada nesse momento não é democracia representativa ou democracia direta. Ela assume uma outra configuração: como articular os avanços da democracia política com a criação de condições mínimas de bem-estar para as grandes massas da população.

Como observa Bobbio (1987), o processo de alargamento da democracia na sociedade contemporânea não deve ocorrer apenas pela integração da democracia representativa com a democracia direta, mas, sobretudo, pela extensão da democratização a corpos diferentes daqueles propriamente políticos. Assinala o referido autor:

... pode-se dizer que, se hoje se deve falar de um desenvolvimento da democracia, ela consiste não tanto [...] na substituição da democracia representativa pela democracia direta, [...] mas na passagem da democracia na esfera política [...] para a democracia na esfera social ... (Bobbio, 1987, p. 155-6).

A ampliação da democracia política deve, necessariamente, estar vinculada com à redução das desigualdades sociais. O significado da democracia fica incompleto se buscar dar conta, unicamente, da democracia como forma de governo.

A defesa da igualdade, no que se refere ao nível de riqueza, é uma utopia nas sociedades capitalistas. Porém, a história tem testemunhado que extremas desigualdades sociais funcionam como fator limitativo da democracia. Desigualdade econômica acentuada conduz, também, à desigualdade política.

Nessa perspectiva, à discussão sobre a ampliação da dimensão política da democracia deve ser incorporado um outro elemento de 
igual importância: a condição sócio-econômica dos atores sociais que estão envolvidos no jogo democrático. Além da elevação do número de eleitores e das instâncias onde eles devem exercer o seu direito de voto, é preciso levar em conta o crescimento qualitativo do eleitorado, no que diz respeito ao seu nível de vida, de escolarização e às condições objetivas de participar das decisões políticas, dos processos administrativos e de exercer o controle sobre os seus representantes.

Democracia politica e bem-estar social em países de capitalismo avançado

Nos países de tradição democrática conquistou-se o sufrágio universal, organizaram-se os sindicatos, criaram-se os partidos de massa, ao mesmo tempo em que foram incorporados, às suas Constituições, institutos de participação direta e mecanismos de aprimoramento da representação, o que resultou no alargamento da dimensão política da democracia.

Os avanços verificados no campo político foram importantes para o surgimento de demandas no sentido da criação de uma infra-estrutura social e da provisão de bens públicos que se colocavam na perspectiva da redução das desigualdades sociais. Ao lado da ampliação da esfera pública, setores organizados dos trabalhadores conseguiram avanços no processo de negociação com os patrões, resultando em melhorias significativas do seu padrão de vida.

É importante reter que, nos países de capitalismo avançado, as políticas sociais numa perspectiva mais abrangente resultaram de uma necessidade intrínseca às mudanças estruturais que estavam se processando. A modernização do processo de trabalho imposta pela chamada terceira revolução industrial resultou numa crescente desmercantilização da força de trabalho. Em decorrência de tal modernização, foi vetado a grandes parcelas da população transformar o seu potencial de trabalho em mercadoria, ou seja, elas não conseguiam mais fazer de sua capacidade de trabalho elemento de sua sobrevivência.

As políticas sociais, nessas circunstâncias, na avaliação de Offe (1989), apresentam-se como a solução para o conjunto das necessidades postas em função das modificações que se operam no 
processo produtivo. Tomando, mais uma vez, Offe como interlocutor, é possível sugerir que, no contexto de tais modificações, o Estado é chamado a organizar uma gama de serviços para "atender" àquelas pessoas que não conseguem (temporária ou definitavamente) ter acesso ao mercado formal de trabalho.

A formulação de políticas sociais mais abrangentes nos países de capitalismo avançado está relacionada, também, com o aperfeiçoamento da democracia política que credenciou as massas, tanto para pressionar o Estado no sentido de ampliar os serviços, os quais funcionavam com salário indireto, quanto para pressionar os patrões por melhores condições de trabalho e salariais.

Os avanços na dimensão política da democracia proporcionaram algumas condições favoráveis para o desenvolvimento do chamado Estado de Bem-Estar Social, o qual, segundo a análise de Bobbio, resultou de "uma resposta a uma demanda vinda de baixo, a uma demanda democrática no sentido pleno da palavra" (1986, p. 35).

É certo que a ampliação dos serviços próprios do Estado Social é produto de pressões decorrentes do exercício da democracia. A extensão do sufrágio e a crescente organização dos trabalhadores tem como desdobramento o crescimento de expectativas das massas que passam a exigir dos poderes constituídos providências políticas.

Outro fator que contribuiu para a ampliação das políticas sociais está relacionado com o papel do Estado enquanto articulador de mecanismos de ordenação de conflitos. Nesse sentido, Cerroni (1993) indica que: "O Estado de Bem-Estar Social cresce sobre a onda de grandes reivindicações e, por isso, também constitui uma resposta cautelar às grandes agitações verificadas após a primeira guerra mundial"(p.155).

Nesses termos, a origem de políticas sociais amplas, próprias do Estado Social, deve ser entendida dialeticamente como resultado da destruição das formas tradicionais de trabalho e de subsistência, decorrentes das mudanças estruturais verificadas nas sociedades capitalistas; das lutas sociais que emergiram, naquele momento, clamando por justiça; e de uma reposta do Estado no sentido de que tais demandas não ultrapassassem a proporções que colocassem em 
cheque o essencial da estrutura social, a qual vinha sendo questionada pelo campo socialista que lutava por transformações mais radicais, visando a eliminação das desigualdades sociais.

A análise efetuada por Offe (1991) sugere que as políticas sociais do Estado de Bem-Estar serviram como a mais importante fórmula de paz para as democracias capitalistas desenvolvidas. Essa fórmula consistiu, fundamentalmente, na obrigação explícita do Estado de proporcionar assistência e apoio, em dinheiro ou em serviço, aos cidadãos que corriam os riscos próprios da sociedade de mercado. Assim, durante todo o período do pós-guerra, segundo o autor, o Estado Social foi celebrado como a solução política para as contradições sociais.

O padrão clássico de Welfare State, que ganhou ampla aceitação após a Segunda Guerra Mundial e foi colocado em prática nos países do primeiro mundo, desenvolveu-se, essencialmente, num período de grande crescimento econômico.

A política adotada nesses países promoveu uma melhoria das condições de vida de amplos setores da classe trabalhadora em todos os sentidos, apesar de permanecer a diferenciação de acordo com a qualificação e o tipo de trabalho realizado. Todavia, o Estado do BemEstar Social significou uma estratégia adotada pelo capitalismo para organizar uma nova forma de reprodução. Ele financiou o capital, e serviu de substrato ideológico para garantir a manutenção da sociedade capitalista, agora em um "novo" patamar: o "capitalismo humanizado".

Daí, a tão decantada propaganda que colocou o Estado do BemEstar Social, nos moldes em que vinha sendo desenvolvido na Europa, como sendo o modelo capaz de propiciar ao cidadão os seus direitos fundamentais de liberdade e bem-estar. Esse padrão estatal teria sido capaz de pôr fim aos conflitos sociais e promover a harmonia entre o capital e o trabalho.

O Estado do Bem-Estar Social parece atender aos interesses de todos, na medida em que tem uma proposta que engloba tanto a reprodução do capital quanto da força de trabalho. Todavia, é essencial ressaltar que isso não elimina o caráter de classe do Estado. Ao delimitar esse padrão de financiamento, o Estado assim o faz para assegurar o status quo da sociedade de classes, permitindo, em última análise, a 
reprodução de uma sociedade calcada na desigualdade e na exploração, mas que, aparentemente, é igualitária e harmônica, ao garantir um mínimo para "quase todos".

A garantia do mínimo para todos está ameaçada, inclusive, nos países do primeiro mundo, na medida em que a demanda por serviços e bens públicos vem crescendo em função da desmercantilização da força de trabalho, por um lado, e por outro, pela retração do Estado no que se refere ao financiamento das políticas de caráter social e sua ampliação no setor de tecnologia de ponta, que favorece diretamente ao capital. A crise do Welfare State se expressa, pois, com mais ênfase do lado da reprodução da força de trabalho do que do lado do capital.

Desde meados da década de 70, o Estado do Bem-Estar passou a enfrentar problemas. Em muitas sociedades capitalistas, a "paz" estabelecida pelas políticas do Bem-Estar tornou-se objeto de dúvida, crítica profunda e de conflito político. É como se "o próprio veículo mais amplamente aceito de solução dos problemas políticos tivesse se tornado problemático, e pelo menos a confiança incondicional no Estado Social e a sua expansão tivessem rapidamente se evaporado" (Offe, 1991, p. 114).

Habermas, citado por Offe (1989), em um nível mais analítico, levantou o problema de que o Estado do Bem-Estar, após haver conciliado, com alguns limites, a tensão entre a economia capitalista e a política democrática, está agora se confrontando com um duplo problema. Enfrenta a desconfiança, de um lado, do núcleo da classe trabalhadora e das categorias sociais em ascensão que abandonaram os ideais coletivistas e, de outro, daqueles que, embora reconhecendo alguma conquista social pelo Estado do Bem-Estar, também se conscientizam de sua contradição interna entre o poder estatal e o 'mundo vivido', ou entre o método do Estado do Bem-Estar e seus objetivos (p. 85).

King (1988) sugere, entretanto, que os esforços crescentes de governos conservadores para restringir o tamanho agregado do setor público não conseguem grandes êxitos, ainda que sua taxa de crescimento tenha diminuído. As despesas com assistência social foram reduzidas em algumas áreas, se bem que num grau significativamente menor do que o originalmente planejado. 
$\mathrm{Na}$ Inglaterra, por exemplo, segundo esse autor, a redução mais dramática verificou-se no setor de habitação pública. No entanto, as despesas públicas em educação, serviços sociais e de saúde e seguridade social cresceram a uma taxa superior à planejada. Nos Estado Unidos, a maioria dos cortes propostos no orçamento do governo Reagan foi aceita pelo congresso, mas houve resistência nos anos subseqüentes. $\mathrm{O}$ impulso nos cortes acordados nos gastos sociais estava na direção planejada pela administração, mas num grau inferior ao desejado. Naquele momento, as despesas com assistência ao desemprego e programas de assistência médica cresceram, se bem que houve redução nos gastos com educação e auxílios a necessitados.

Obviamente, a condição de cidadania que serviu de base para a edificação do tipo clássico de Welfare (classificado por Ascoli, 1984 como institucional-redistributivo), voltado para garantir a todos os cidadãos, amplos bens e serviços produzidos e criados pelo Estado e distribuídos gratuitamente com base em critérios universalistas, está historicamente sendo posta em xeque pelas contradições próprias da sociedade organizada, tendo por base a valorização do capital. Esse padrão foi "exequíivel" até o momento em que o processo de acumulação suportou financiar, em decorrência do grande crescimento econômico, um certo nível de bem-estar, sem ameaçar as taxas de lucro.

A esfera pública erigida nesses países foi capaz de propiciar as condições favoráveis à reprodução ampliada do capital e do trabalho em níveis "aceitáveis", além de prestar assistência àqueles que foram postos à margem do processo de trabalho. No entanto, a crise que começou a se configurar a partir da década de setenta tem imposto limites a tal padrão de bem-estar, inclusive para os setores que estão integrados ao processo de trabalho.

Assim, mesmo reconhecendo os ganhos sociais advindos das chamadas políticas de bem-estar, é preciso ressaltar que no final do século $\mathrm{XX}$ não são raras as evidências de que, na maioria dos países do primeiro mundo, as condições de vida de certos setores da população são cada vez mais precárias. Evidencia-se, dessa forma, a existência de um sistema social em que há cidadãos, de fato, e "cidadãos" cujos direitos têm a sua realização assegurada apenas no nível formal. 
Esse é um quadro que tende a agravar-se visto que o Estado, sob a égide do neoliberalismo, se move no sentido de reduzir a amplitude das políticas sociais.

No contexto das políticas neoliberais, começam a tomar corpo e ganhar adeptos as idéias de descentralização, participação e de autogestão para gerir e administrar a política social, agora não mais da abundância, que caracterizou o seu período áureo, mas da escassez própria do momento de crise. Assim, parece ser possível aventar a hipótese de que estão se constituindo "novos" padrões de políticas sociais, diversos daquele do tipo clássico, que indicam uma mudança no comportamento do Estado, tanto na concepção como na gestão das políticas públicas, adequando-as às circunstâncias do momento atual. O eixo da "cidadania" fica deslocado do atendimento amplo às necessidades básicas do cidadão (política centralizada do Welfare), para o atendimento mínimo com participação dos clientes sob a custódia direta ou indireta do Estado.

A dimensão econômica da democracia, circunscrita aos limites do capitalismo, não pode, pois, entrar em contradição com a lógica que rege a organização desse tipo de sociedade. A redistribuição de renda será sempre efetuada dentro de parâmetros que não ameacem a propriedade privada dos meios de produção, não eliminem a diferenciação de classe, e nem mesmo, comprometam, em algum nível, as taxas de lucro.

Pode-se afirmar, todavia, que nos países onde a democracia política foi aperfeiçoada, criaram-se as condições objetivas para desencadear o processo, ainda que restrito, de redistribuição de renda, ocorrendo uma considerável incorporação da população ao sistema educacional. Em outras palavras, verificou-se uma certa articulação entre as dimensões política, econômica e cultural da democracia, não significando, porém, que todos tenham usufruído igualmente dos benefícios advindos de tal articulação.

\section{Democracia política e "bem-estar" no Brasil}

As particularidades históricas do desenvolvimento do capitalismo, em países como o Brasil, imprimem à democracia características 
diversas daquele padrão clássico das experiências de países de capitalismo avançado.

As especificidades brasileiras traduzem-se na edificação de uma sociedade com pouca ou quase nenhuma tradição democrática. Nela o conservadorismo está imbricado, não apenas no aparelho de Estado, mas atravessa, de ponta a ponta, toda a sociedade civil. As regras do jogo democrático, definidas predominantemente pelas elites em função dos seus interesses particulares, têm dificultado tanto a participação política mais abrangente da sociedade civil, principalmente das massas desorganizadas, quanto o acesso aos bens materiais e culturais socialmente produzidos.

$\mathrm{O}$ autoritarismo tem se expressado, até mesmo, nos períodos em que a democracia desponta como horizonte político para a vida brasileira. O processo de democratização no Brasil tem sido, assim, historicamente, perpassado por uma série de contradições que têm dificultado a ampliação da democracia.

Isso não significa negar que vêm ocorrendo, no país, principalmente nas últimas décadas, algumas inovações no campo da democracia política, traduzidas pelo aumento do número de eleitores que tem comparecido às eleições nos últimos pleitos, pela organização crescente dos trabalhadores em sindicatos e pela inclusão, na Constituição de 1988, de elementos de aprimoramento da democracia política, como o plebiscito, o referendo, a iniciativa popular, e o direito público subjetivo à obrigatoriedade do acesso ao ensino.

Se no campo político, verificaram-se avanços democráticos, ainda que limitados, no plano dos diretos sociais não ocorreram alterações significativas, uma vez que o crescimento econômico no Brasil não foi acompanhado da adoção de programas sociais amplos capazes de modificar o quadro social.

É interessante notar que grande parte dos ganhos conquistados e formalmente incluídos na Constituição de 1988 não foram regulamentados e nem postos em prática, ou foram, em alguns casos, beneficiando apenas determinados segmentos da sociedade. Na década de 90 , inclusive, as políticas neoliberais adotadas pelos dois últimos governos vêm ameaçando alguns ganhos sociais conquistados. Assim, a seleti- 
vidade/exclusão continuam sendo a marca registrada das políticas sociais no Brasil.

Oliveira (1990), analisando a economia brasileira, sugere que ela é caracterizada por uma regulação truncada, isto é, marcada simultaneamente pela ausência de regras estáveis, de direitos, e pela existência de uma regulação caso a caso. As políticas, coerentemente com essa perspectiva econômica, atendem, quase sempre, a interesses de grupos empresariais específicos, dificultando, assim, a elaboração de políticas gerais e abrangentes.

As políticas sociais também não fogem a essa regra. Elas têm se caracterizado pela falta de políticas universalistas, tais como as políticas de bem-estar praticadas em países do chamado primeiro mundo, constituindo-se, portanto, num padrão seletivo, perpassado por sua vez, pelo clientelismo e pelo fisiologismo político. Assim, não é pertinente discutir a política social tomando como referência o padrão clássico de Welfare próprio dos países desenvolvidos, uma vez que, historicamente, o nosso modelo não adquiriu características que o aproximassem de tal padrão.

No quadro brasileiro, o padrão de financiamento adotado pelo Estado tem favorecido ao capital em detrimento do trabalho, com muito mais ênfase do que nos países do primeiro mundo. Ele desenvolveu, de um lado, uma ampla política de beneficiamento do capital, especificamente no que concerne ao investimento na indústria de base, a juros subsidiados, a empréstimos a fundo perdido e à tecnologia. Do outro lado, pôs em prática uma política social seletiva e assistencialista perpassada, por sua vez, pelo clientelismo e agravada pela corrupção.

Não se desconhece, no entanto que, gradativamente, o Estado brasileiro vem ampliando a oferta de bens e serviços públicos, pelo menos em termos quantitativos, em alguns setores e para algumas faixas da população. São, todavia, serviços de qualidade precária (por exemplo, saúde e educação básica). Ao lado dessa ampliação seletiva assiste-se, também, a uma certa tendência, mais ao nível do discurso do que da prática, para criar mecanismos de participação popular na gestão e controle das políticas sociais. Em relação ao financiamento do capital, existe uma forte inclinação para aumentar os gastos com 
tecnologia, com vistas a modernizar a indústria e buscar um padrão de competitividade no cenário internacional.

Tem-se, pois, no Brasil, uma esfera pública que passou a ser o pressuposto da reprodução privilegiada do capital de um lado, e, de outro, da reprodução seletiva e limitada da força de trabalho. O Estado pôs em prática uma política de subsídios que beneficiou de forma ampla as elites empresariais, porém, foi incapaz de implementar uma política social para reduzir a crescente desigualdade social existente no país.

Diante de tais circunstâncias, torna-se difícil fazer referência ao Estado de Bem-Estar Social no Brasil, uma vez que a política posta em prática, nesse país, apesar de incorporar, em nível de discurso, princípios teóricos que serviram de fundamento às políticas de Welfare State, tem demarcado, do ponto de vista prático, mais uma situação de "mal-estar" do que de bem-estar para amplos setores da sociedade.

Manzini-Covre (1994), lançando um olhar comparativo sobre as realidades sociais brasileira e italiana, indica que “(o) Brasil [...] não apresenta quadro de seguridade social, persiste mais a 'inseguridade' social, a violência, a exclusão social, a miséria, o extermínio de crianças. [...] O Brasil conhece o Estado do Mal-Estar"(p. 179).

No Brasil, tem-se uma democracia perpassada por contradições de ordem política e econômica. Entre nós parece ser plausível a hipótese de que as desigualdades econômicas funcionem como um fator limitativo da democracia. Isso porque a ampliação das dimensões política e cultural da democracia estão intimamente ligadas à criação de condições sociais mínimas para permitir ao cidadão participar do jogo democrático.

Esse posicionamento não representa a defesa da tese segundo a qual basta haver um mínimo de bem-estar social para que se avance no processo de democratização da sociedade. Políticas sociais mais amplas nem sempre são resultantes de propostas de governos democráticos. Existem evidências de que alguns países em períodos de autoritarismo foram capazes de conceber programas sociais com um nível de cobertura relativamente amplo. O Brasil, por exemplo, construiu o seu núcleo de políticas sociais em períodos de extremo autoritarismo. Porém, se não existe uma relação de causa e efeito entre 
condições sociais mínimas e democracia, não se pode desprezar a influência que a primeira exerce sobre a segunda.

Entende-se, como O'Donnell (1988), que uma sociedade como a brasileira - que carrega a pesada herança da escravidão, e na qual a burguesia não foi submetida à experiência civilizadora de ter que se defrontar e negociar com sua contraparte de classe - tem enormes dificuldades em todos os planos, inclusive no político, para reconhecer e institucionalizar a diversidade dos outros. Nessas circunstâncias, a tarefa de construir, no país, uma democracia política inclui, portanto, o esforço para alcançar graus razoáveis de modernização e de democratização de certas relações sociais (a começar pelas do trabalho) e do papel do Estado (a começar pelas políticas sociais).

\section{Conclusão}

A conclusão esboçada neste artigo encaminha-se na perspectiva de reconhecer que a ampliação da dimensão política da democracia não garante, necessariamente, a democratização dos bens materiais e culturais socialmente produzidos. Porém, é preciso reter que tal ampliação gera determinadas condições que favorecem a organização da sociedade civil, credenciando-a para encaminhar suas reivindicações de forma mais ordenada.

Enfim, pode-se indicar - e aqui uma vez mais estamos tomando Bobbio como interlocutor - que a ampliação da democracia coloca-se contemporaneamente como uma meta que deve ser buscada. Tal ampliação requer a incorporação organizada dos atores sociais, tanto em processos políticos, quanto em processos administrativos. Aliado a isso indica-se, também, a necessidade da criação de condições sociais aceitáveis para que a população possa se credenciar para participar de tais processos. Isto significa que a democracia, contemporaneamente, não pode se consolidar, senão quando encerre em seus limites as dimensões que traduzem o social, o político e o cultural.

\section{Referências}

Ascoli, U. (1984). Il sistema italiano de Welfare. In (Org.), Welfare State all'italiana. Roma-Bari: Laterza. 
Bobbio, N. (1979). Quais as alternativas para a democracia representativa. In O marxismo e o Estado. (pp. 33-54). Rio de janeiro: Graal.

Bobbio, N. (1986). O futuro da democracia; um desafio das regras do jogo ( $5^{\mathrm{a}}$. ed.). Rio de Janeiro: Paz e Terra.

Bobbio, N. (1987). Estado governo sociedade; para uma teoria geral da política (2a. ed.). Rio de Janeiro: Paz e Terra.

Bobbio, N. (1993). Liberalismo e democracia (4 ${ }^{\mathrm{a}}$. ed.). São Paulo: Brasiliense.

Burns, E. M. (1957). História da civilização ocidental (4a. ed.). Rio de Janeiro, Porto Alegre, São Paulo: Globo.

Cerroni, U. (1993). Política: métodos, teorias, processos, sujeitos, instituições, categorias (M. A. Nogueira, Trad.). São Paulo: Brasiliense.

Manzinni-Covre, M. de L. (1994). Fragmentos de uma cidadania; um estudo na Itália para pensar o Brasil. São Paulo. Tese de Livredocência não-publicada, Faculdade de Educação, Universidade de São Paulo, São Paulo.

Finley, M. I. (1988). Democracia antiga e moderna (W. Barcellos \& S. Bedran, Trad.). Rio de Janeiro: Graal.

Gruppi, L. (1980). Tudo começou com Maquiavel. Porto Alegre: L\&PM.

King, D. (1988). O Estado e as estruturas de bem-estar. Novos estudos CEBRAP, 22, 53-76.

Locke, J. (1983). Segundo tratado sobre o governo. In: Os pensadores ( $3^{\text {a }}$.ed., pp. 33-131). São Paulo: Abril Cultural.

Marshall, T. H (1967). Cidadania, classe social e status. (M. P. Gadelha, Trad.). Rio de Janeiro: Zahar.

Montesquieu, C. L. de S. (1979). Do espírito das leis. In Os Pensadores. ( $2^{\mathrm{a}}$.ed.). São Paulo: Abril Cultural.

O’Donnell, G. (1988). Hiatos, instituições e perspectivas democráticas. In F.W. Reis \& G. O'Donnell (Orgs.), A democracia no Brasil: dilema e perspectivas (pp. 72-90). São Paulo: Vértice.

Offe, C. (1989). Capitalismo desorganizado. (W. C. Brant, Trad.). São Paulo: Brasiliense.

Offe, C. (1991). Trabalho e sociedade: problemas estruturais e perspectivas para o futuro da sociedade do trabalho (v. 2, G. Bayer \& M. Martencic, Trad.). Rio de Janeiro: Tempo Brasileiro.

Oliveira, F. de (1990). O protagonista do drama; Estado e sociedade no Brasil. In S. Laranjeira (Org.), Classes e movimentos sociais na América Latina (pp. 41-66). São Paulo: Hucitec. 
312 A. Cabral Neto

Pateman, C. (1992). Participação e teoria democrática (L. P. Rouanet, Trad.). Rio de Janeiro: Paz e Terra.

Paulo Netto, J. (1990). Democracia e transição socialista: escritos de teoria política. Belo Horizonte: Oficina de Livros.

Rousseau, J. J. (1983). Do contrato social. In Os pensadores ( $3^{\text {a }}$.ed., pp. 15-145). São Paulo: Abril Cultural.

Antonio Cabral Neto é professor do Programa de Pós-Graduação em Educação da Universidade Federal do Rio Grande do Norte. Doutor em Educação pela Universidade de São Paulo. Endereço para correspondência: Grupo de Pesquisas Marxismo \& Educação, DEPSI/UFRN, Caixa Postal 1622, 59078-970, Natal, RN. E-mail: marxismo@cchla.ufrn.br.
${ }^{1}$ Artigo elaborado a partir de nossa Tese de Doutarado do autor, "Educação e Democratização no Projeto Nordeste: a memória reconstruída”, defendida na Faculdade de Educação da Universidade de São Paulo.

Sobre o autor 